\title{
Heat capacities and thermodynamic properties of antimony substituted lanthanum orthoniobates.
}

\author{
Aleksandra Mielewczyk-Gryn*1, Sebastian Wachowski ${ }^{1}$, Judyta Strychalska ${ }^{1}$, Krzysztof Zagórski $^{1}$, \\ Tomasz Klimczuk ${ }^{1}$, Alexandra Navrotsky ${ }^{2}$ and Maria Gazda ${ }^{1}$ \\ ${ }^{1}$ Faculty of Applied Physics and Mathematics, Gdansk University of Technology, Narutowicza 11/12, 80-233 \\ Gdansk, Poland
}

${ }^{2}$ Peter A. Rock Thermochemistry Laboratory and NEAT ORU, University of California Davis, Davis CA 95616 USA

*corresponding author: amielewczyk@mif.pg.gda.pl, +48 583486619

\begin{abstract}
The results of heat capacity measurements for the lanthanum orthoniobate substituted with 10 , 20 and $30 \mathrm{~mol} \%$ of antimony $\left(\mathrm{LaNb}_{0.9} \mathrm{Sb}_{0.1} \mathrm{O}_{4}, \mathrm{LaNb}_{0.8} \mathrm{Sb}_{0.2} \mathrm{O}_{4}\right.$ and $\left.\mathrm{LaNb}_{0.7} \mathrm{Sb}_{0.3} \mathrm{O}_{4}\right)$ are presented and discussed. Temperature dependence of low temperature heat capacity was analyzed within the Debye and Einstein models. The Debye temperature decreased, whereas the Einstein temperature increased with antimony content. The decrease of the Debye temperature with increasing antimony content was correlated with decreasing scheelite - fergusonite transition temperature. The increase of the Einstein temperature of $\mathrm{LaSb}_{\mathrm{x}} \mathrm{Nb}_{1-\mathrm{x}} \mathrm{O}_{4}$ with increasing antimony content may indicate increasing frequency of optical vibrations of $\mathrm{Nb}(\mathrm{Sb})-\mathrm{O}_{4}^{-2}$ polyhedra relative to $\mathrm{La}^{+3}$ cations. Using the heat capacity data, standard entropies of the phases were calculated and combined with previously measured enthalpies of formation to obtain Gibbs energies of formation. Standard thermodynamic properties were tabulated.
\end{abstract}

Keywords: lanthanum orthoniobate, heat capacity, Debye temperature, Einstein temperature, entropy, Gibbs energy

\section{Introduction}

Understanding the thermodynamic properties of ceramic materials operating in a wide temperature range is crucial in terms of applications and from the geochemical point of view. In this work we focus on lanthanum orthoniobates, that is, on compounds based on $\mathrm{LaNbO}_{4}$ stoichiometry. Properties of these materials may be modified by different substitutions. For example, temperature of the structural phase transition from the monoclinic to the tetragonal phase depends on the type and amount of substituting atoms. The phase transition temperature of stoichiometric $\mathrm{LaNbO}_{4}$ is about $770 \mathrm{~K}$ [1] but it may be either decreased or increased if $\mathrm{Nb}$ is partially substituted by other elements. For instance, substituting niobium by an element with higher ionic radius, such as Ta, leads to increase of the phase transition temperature [2,3]. However, particularly interesting is the possibility of decreasing the transition temperature below room temperature which may be achieved through 
substitution with antimony or vanadium [4-8]. In our previous work we analyzed the influence of antimony substitution on the spontaneous strain and Landau order parameter [7] . It was shown that the introduction of antimony atoms into the niobium sublattice does not change the nature of the phase transition which is second order. Further investigation by high temperature oxide melt solution calorimetry has allowed us to analyze the energetic stability of materials containing different concentrations of substituent. The investigation showed that the enthalpy of structural phase transition for these compounds is relatively low [7]. In the present work, heat capacity measurements at $2-870$ $\mathrm{K}$ for lanthanum orthoniobate substituted by 10, 20 and 30 mole \% of antimony are presented and discussed. Standard entropies and Gibbs energies of formation are calculated.

\section{Experimental Methods}

The $\mathrm{LaNbO}_{4}, \mathrm{LaNb}_{0.9} \mathrm{Sb}_{0.1} \mathrm{O}_{4}, \mathrm{LaNb}_{0.8} \mathrm{Sb}_{0.2} \mathrm{O}_{4}$ and $\mathrm{LaNb}_{0.7} \mathrm{Sb}_{0.3} \mathrm{O}_{4}$ samples were synthesized as described elsewhere [4]. The sintered samples were crushed into powder and analyzed by powder Xray diffraction using a Phillips X'Pert Pro MPD diffractometer with $\mathrm{Cu} \mathrm{K}_{\alpha}$ radiation. Single phase pulverized samples were then analyzed in order to determine their high temperature heat capacity. Heat capacity at high temperature $(350-870 \mathrm{~K})$ was measured by a Setaram LabSYSevo system. Measurements were undertaken in $\mathrm{Pt}$ crucibles; the system was calibrated by $\mathrm{Al}_{2} \mathrm{O}_{3}$ prior measurements and purged by argon during measurements. Heat capacity measurements (thermal relaxation technique) in the temperature range $1.9<\mathrm{T}<300 \mathrm{~K}$ were carried out using a Quantum Design Physical Property Measurement System (PPMS). The accuracy of Cp measurements was established to be approximately $3 \%$ and $0.5 \%$ at high (LabSYSEvo), and low temperatures (PPMS system), respectively. All errors of calculated values were calculated by error propagation.

\section{Results and Discussion}

The low and high temperature heat capacities are depicted in Fig. 1. All heat capacity vs. temperature curves are similar. Below $300 \mathrm{~K}$ (Fig. 1a) heat capacity monotonically increases with temperature, whereas in the high temperature range it first slowly increases and above $550 \mathrm{~K}$ it may decrease slightly (Fig. 1b). An average value of $\mathrm{C}_{\mathrm{p}}$ between $400 \mathrm{~K}$ and $900 \mathrm{~K}$ is close to the Dulong and Petit $3 n R$ value, where $R$ is the gas constant and $n$ is the number of atoms in the formula unit, namely six for $\mathrm{LaNb}_{1-\mathrm{x}} \mathrm{Sb}_{\mathrm{x}} \mathrm{O}_{4}$. A possible small decrease of heat capacity above $550 \mathrm{~K}$ may be caused by a loss of gases $(<5 \%$ total weight loss) from the material, and is not considered significant within the error of DSC measurements. Indeed water and carbon dioxide desorption from $\mathrm{La}_{0.98} \mathrm{Mg}_{0.02} \mathrm{NbO}_{4}$ in argon atmosphere was observed at 633, 733 and 948 K [9]. Sarin et al. also observed a weak decrease of $\mathrm{C}_{\mathrm{p}}$ in high temperatures in rare earth orthoniobates [10].

In order to study the influence of the antimony substitution on heat capacity of $\mathrm{LaNb}_{1-\mathrm{x}} \mathrm{Sb}_{\mathrm{x}} \mathrm{O}_{4}$ the temperature dependence of heat capacity in the low temperature range was analyzed. In general, heat capacity includes contributions from electronic, harmonic, dilatational and anharmonic terms. In 
the present analysis corrections for dilatation and anharmonicity were not included. Low temperature heat capacity temperature dependence was analyzed in two steps. First, the data below approximately $8 \mathrm{~K}$ were fitted with equation(1)

$$
C_{p}=\gamma T+\beta T^{3}
$$

where the first and the second terms correspond to the electronic and phonon contributions to the specific heat, respectively. The value of $\beta$ parameter of the phonon term, described by equation (2), allows determining the Debye temperature $\left(\theta_{\mathrm{D}}\right)$.

$$
\beta=\frac{12 \pi^{4}}{5 \theta_{D}^{3}} n R, \quad n=6
$$

The second step of the data analysis was performed in the temperature range $8-300 \mathrm{~K}$. In this case the contribution of optical phonons should be also taken into account, so that, the phonon heat capacity was treated as the sum of Debye and Einstein terms. The following formula was used:

$$
C_{p}=\gamma T+k C_{\text {Debye }}+(1-k) C_{\text {Einstein }}
$$

where $\mathrm{k}$ is the weight of the Debye term. Debye and Einstein heat capacities are described by equations (4) and (5).

$$
\begin{aligned}
& C_{\text {Debye }}=9 n R\left(\frac{T}{\theta_{D}}\right)^{3} \int_{0}^{x_{D}} \frac{x^{4} e^{x}}{\left(e^{x}-1\right)^{2}} d x \\
& C_{\text {Einstein }}=3 n R\left(\frac{\theta_{E}}{T}\right)^{2} e^{\frac{\theta_{E}}{T}}\left(e^{\frac{\theta_{E}}{T}}-1\right)^{2}
\end{aligned}
$$

where $\theta_{\mathrm{D}}$ and $\theta_{\mathrm{E}}$ are Debye and Einstein temperatures, respectively, $\mathrm{n}$ is the number of atoms in the formula unit (6) and $x_{D}$ is $\theta_{D} / T$. The Debye temperatures and $\gamma$ parameters determined in the first step of low temperature analysis were used as starting parameters. The three acoustic or optical branches were considered as degenerate.

The fitting of the low temperature heat capacity is shown in Fig. 2, where heat capacity divided by temperature is plotted as a function of $\mathrm{T}^{2}$. In agreement with relation (1), the plots are linear for temperature below approximately $8 \mathrm{~K}$. The lines intercept the zero point, which means that the $\gamma$ parameters are small. $0.19 \pm 0.10,0.0 \pm 0.1,0.01 \pm 0.04$, and $0.36 \pm 0.05 \mathrm{~mJ} \mathrm{~mol}^{-1} \mathrm{~K}^{-2}$ for $\mathrm{LaNbO}_{4}, \mathrm{LaNb}_{0.9} \mathrm{Sb}_{0.1} \mathrm{O}_{4}, \mathrm{LaNb}_{0.8} \mathrm{Sb}_{0.2} \mathrm{O}_{4}$ and $\mathrm{LaNb}_{0.7} \mathrm{Sb}_{0.3} \mathrm{O}_{4}$, respectively. This confirms that these 
materials are electronic insulators and the electronic contribution to the heat capacity is negligible. The slopes of the lines as well as the temperature range in which the plots are linear depend on the antimony content. Table 1 summarizes the values of Debye temperature. $\theta_{\mathrm{D}}$ decreases with increasing antimony content. The larger atomic mass of antimony than of niobium could be responsible for this decrease. However, a decrease of Debye temperature has been observed previously by Nevitt and Knapp for vanadium substituted lanthanum orthoniobate [11], despite the lower atomic mass of $\mathrm{V}$ than of $\mathrm{Nb}$, so some other factors may also contribute to the changes with dopant. Low temperature heat capacity is dominated by acoustic phonon modes. Moreover, it has been reported that the scheelite fergusonite phase transition is associated with acoustic phonon mode softening in the scheelite phase [12]. Raman scattering studies showed that the force constant between the nearest $(\mathrm{Nb}, \mathrm{V}) \mathrm{O}_{4}$ tetrahedral units softens at $T_{c}$ as a function of vanadium content [13]. Therefore, as suggested by Nevitt and Knapp, decreasing Debye temperature with increasing vanadium content in $\mathrm{LaNb}_{1-\mathrm{x}} \mathrm{V}_{\mathrm{x}} \mathrm{O}_{4}$ indicates an increase in the low temperature acoustic phonon density of states, which may be associated with a decreasing structural phase transition temperature [6]. In the present study of antimony substituted lanthanum orthoniobate, similar tendencies, namely a decrease of both Debye and transition temperatures with increasing antimony content, are observed. Figure 3 shows the relation between Debye temperature and the scheelite-fergusonite transition temperatures in both vanadium and antimony substituted lanthanum orthoniobates.

Although the data points for antimony substituted lanthanum orthoniobate fall slightly below those of vanadium substituted compounds, the relations between $\theta_{\mathrm{D}}$ and transition temperature are qualitatively similar. This similarity between $\mathrm{LaNb}_{1-\mathrm{x}} \mathrm{V}_{\mathrm{x}} \mathrm{O}_{4}$ and $\mathrm{LaNb}_{1-\mathrm{x}} \mathrm{Sb}_{\mathrm{x}} \mathrm{O}_{4}$ supports the interpretation given by Nevitt and Knapp. The lower values of $\theta_{D}$ of antimony substituted lanthanum orthoniobate in comparison with vanadium substituted compounds are most probably caused by the lower atomic mass of vanadium than of antimony.

An example of the fitting of the high temperature heat capacity, performed with the use of equation (3), is depicted in Fig. 4. The Debye contribution calculated from equation (4) using the Debye temperature determined on the basis of low temperature data does not describe the total heat capacity above approximately $70 \mathrm{~K}$. The presence of higher energy optical modes is then represented by the Einstein term. The Einstein temperatures determined on the basis of the fitting are collected in Table 1.

In contrast to the Debye temperature, the Einstein temperature of $\mathrm{LaNb}_{1-\mathrm{x}} \mathrm{Sb}_{\mathrm{x}} \mathrm{O}_{4}$ increases with increasing antimony content. The optical phonon modes which are responsible for the Einstein temperature are probably not relevant for the structural transformation of lanthanum orthoniobate [11]. Direct information concerning optical phonon characteristics of lanthanum orthoniobate is scarce, however similar compounds, i.e. $\mathrm{SrWO}_{4}, \mathrm{CaWO}_{4}, \mathrm{SrMoO}_{4}$ and $\mathrm{CaMoO}_{4}$, have been studied [14,15]. Senyshyn et al. analyzed contributions of particular atoms to the $\mathrm{CaMoO}_{4}$ phonon density of states and showed that molybdenum and oxygen atoms dominate both the low-frequency lattice modes and 
the internal modes of $\mathrm{MoO}_{4}{ }^{-2}$ polyhedra, whereas calcium dominates the intermediate frequency region of the phonon spectrum [14]. Porto et al. showed that the wave numbers of optical phonon modes related to the low frequency external vibrations in which the $\mathrm{W}(\mathrm{Mo})-\mathrm{O}_{4}^{-2} \mathrm{ox}$ ions move as rigid units are between 75 and $219 \mathrm{~cm}^{-1}$, whereas those of internal $\mathrm{W}(\mathrm{Mo})-\mathrm{O}_{4}{ }^{-2}$ unit vibrations are between 202 and $925 \mathrm{~cm}^{-1}$ [15]. Assuming that lanthanum orthoniobate has similar vibrational properties as these $\mathrm{ABO}_{4}$ compounds described above, at temperature below $300 \mathrm{~K}$ external vibrations should make the major contribution to the heat capacity, but also a contribution of internal modes may be expected. In the studied niobates the external and internal vibrations are those of the $\mathrm{Nb}(\mathrm{Sb})-\mathrm{O}_{4}{ }^{-2}$ polyhedra relative to $\mathrm{La}^{+3}$ cations and the internal vibrations of the $\mathrm{Nb}(\mathrm{Sb})-\mathrm{O}_{4}{ }^{-2}$ polyhedra, respectively. This means that in both cases a decrease of frequency related to the increasing mass of the vibrating entities could be expected. The observed opposite tendency may indicate that hardening of the force constant between $\mathrm{Nb}(\mathrm{Sb})-\mathrm{O}_{4}^{-2}$ anion and $\mathrm{La}^{+3}$ cation occurs as a result of increasing antimony content.

In the high temperature range, heat capacity of antimony substituted lanthanum orthoniobates depends weakly on temperature. As seen in Fig. 1b, no change of heat capacity at temperature of the phase transition can be observed. This indicates that the enthalpy and any change in heat capacity associated with the scheelite - fergusonite transition is very low. Nevitt and Knapp found no measurable change in heat capacity at the transition temperature of either pure $\mathrm{LaNbO}_{4}$ or vanadium substituted lanthanum orthoniobate [11]. On the other hand, Sarin et al. reported a $4 \%$ step in $\mathrm{C}_{\mathrm{p}}$ around the transition temperature of $\mathrm{LaNbO}_{4}, \mathrm{YNbO}_{4}$ and $\mathrm{DyNbO}_{4}[10]$. The low value of heat capacity change or phase transition enthalpy in the scheelite - fergusonite transition is consistent with our previous results on lanthanum orthoniobate where the difference between the enthalpies of formation of the monoclinic and tetragonal orthoniobates has been found to be very low [7]. Similar to high temperature measurements, $\mathrm{Cp}$ in the low temperature region shows no detectable transition for the sample with $30 \mathrm{~mol} \%$ doping, which presumably undergoes such a transition below room temperature.

Once fits to heat capacities were determined, smoothed heat capacities and thermodynamic data were generated for the range of temperature of 2- $300 \mathrm{~K}$ and are presented in Table 2. Using values of enthalpies of formation from our previous work [7], standard molar entropies, enthalpies and Gibbs energies of formation from oxides and elements are given in Table 3. The thermodynamic parameters for all three compositions are similar with a slight rise of standard entropy with increasing antimony content.

\section{Conclusions}

The heat capacity of the lanthanum orthoniobate substituted with 10, 20 and $30 \%$ of antimony was measured in the temperature ranges $4-300 \mathrm{~K}$ and $350-870 \mathrm{~K}$. The Debye and Einstein temperatures were determined on the basis of the heat capacity temperature dependence below $300 \mathrm{~K}$. 
A decrease of the Debye temperature with increasing antimony content was correlated with decreasing scheelite - fergusonite transition temperatures. The observed increase of the Einstein temperature of $\mathrm{LaSb}_{\mathrm{x}} \mathrm{Nb}_{1-\mathrm{x}} \mathrm{O}_{4}$ with increasing antimony content may be caused by an increase in the frequency of vibrations in which the $\mathrm{Nb}(\mathrm{Sb})-\mathrm{O}_{4}^{-2}$ oxyions move as rigid units. There is no observable change in the heat capacity at the scheelite - fergusonite transition, consistent with previously measured heats of formation which suggest a very small enthalpy of transformation.

\section{Acknowledgments}

The research performed at Gdansk University of Technology was financially supported by the National Science Centre (Poland) Grant No. DEC-2012/07/E/ST3/00584. Sample preparation and other work at UC Davis was supported by the U.S. National Science Foundation (grant EAR 13-21410).

\section{References}

[1] W.M. Kriven, P. Sarin, L.F. Siah, Phase Transformations in Rare Earth Niobates, Solid-Solid Phase Transform. Inorg. Mater. (2005) 1015 - 1022.

[2] F. Vullum, F. Nitsche, S.M. Selbach, T. Grande, Solid solubility and phase transitions in the system $\mathrm{LaNb}_{1-\mathrm{x}} \mathrm{Ta}_{\mathrm{x}} \mathrm{O}_{4}$, J. Solid State Chem. 181 (2008) 2580-2585. doi:10.1016/j.jssc.2008.06.032.

[3] A.B. Santibáñez-Mendieta, E. Fabbri, S. Licoccia, E. Traversa, Tailoring phase stability and electrical conductivity of $\mathrm{Sr}_{0.02} \mathrm{La}_{0.98} \mathrm{Nb}_{1-\mathrm{x}} \mathrm{Ta}_{\mathrm{x}} \mathrm{O}_{4}$ for intermediate temperature fuel cell proton conducting electrolytes, Solid State Ionics. 216 (2012) 6-10. doi:10.1016/j.ssi.2011.09.019.

[4] S. Wachowski, A. Mielewczyk-Gryn, M. Gazda, Effect of isovalent substitution on microstructure and phase transition of $\mathrm{LaNb}_{1-\mathrm{x}} \mathrm{M}_{\mathrm{x}} \mathrm{O}_{4}(\mathrm{M}=\mathrm{Sb}, \mathrm{V}$ or ta; $\mathrm{x}=0.05$ to 0.3$)$, J. Solid State Chem. 219 (2014) 201-209.

http://www.sciencedirect.com/science/article/pii/S0022459614003466.

[5] A. Mielewczyk-Gryn, K. Gdula, T. Lendze, B. Kusz, M. Gazda, Nano- and microcrystals of doped niobates, Cryst. Res. Technol. 45 (2010) 1225-1228. doi:10.1002/crat.201000378.

[6] A. Mielewczyk-Gryn, K. Gdula-Kasica, B. Kusz, M. Gazda, High temperature monoclinic-totetragonal phase transition in magnesium doped lanthanum ortho-niobate, Ceram. Int. 39 (2013) 4239-4244. doi:10.1016/j.ceramint.2012.09.102.

[7] A. Mielewczyk-Gryn, S. Wachowski, K.I. Lilova, X. Guo, M. Gazda, A. Navrotsky, Influence of antimony substitution on spontaneous strain and thermodynamic stability of lanthanum orthoniobate, Ceram. Int. 41 (2015) 2128-2133. doi:10.1016/j.ceramint.2014.10.010. 
[8] A.D. Brandão, I. Antunes, J.R. Frade, J. Torre, V. V. Kharton, D.P. Fagg, Enhanced LowTemperature Proton Conduction in $\mathrm{Sr}_{0.02} \mathrm{La}_{0.98} \mathrm{NbO}_{4-\delta}$ by Scheelite Phase Retention, Chem. Mater. 22 (2010) 6673-6683. doi:10.1021/cm102705e.

[9] A. Mielewczyk-Gryn, S. Wachowski, K. Zagórski, P. Jasiński, M. Gazda, Characterization of magnesium doped lanthanum orthoniobate synthesized by molten salt route, Ceram. Int. 41 (2015) 7847-7852. doi:10.1016/j.ceramint.2015.02.121.

[10] P. Sarin, R.W. Hughes, D.R. Lowry, Z.D. Apostolov, W.M. Kriven, High-Temperature Properties and Ferroelastic Phase Transitions in Rare-Earth Niobates (LnNbO 4 ), 3319 (2014). doi:10.1111/jace.13095.

[11] M. V. Nevitt, G.S. Knapp, Phonon properties of vanadium-substituted lanthanum niobate derived from heat-capacity measurements, J. Phys. Chem. Solids. 47 (1986) 501-505. doi:doi:10.1016/0022-3697(86)90049-1.

[12] K. Parlinski, Y. Hashi, S. Tsunekawa, Y. Kawazoe, Computer simulation of ferroelastic phase transition in $\mathrm{LaNbO}_{4}$, J. Mater. Res. 12 (1997) 2428-2437. doi:10.1557/JMR.1997.0321.

[13] M.H.G. and M.V.N. A. T. Aldred, S.-K. Chan, A. T. Aldred, S.-K. Chan, M. H. Grimsditch and M. V. Nevitt Displacive Phase Transformation in Vanadium - Substituted Lanthanum Niobate 1983 MRS Meeting. MRS Proceedings / Volume 24 / 1983, 24 (1983) 1983.

[14] a. Senyshyn, H. Kraus, V. Mikhailik, L. Vasylechko, M. Knapp, Thermal properties of $\mathrm{CaMoO}_{4}$ : Lattice dynamics and synchrotron powder diffraction studies, Phys. Rev. B. 73 (2006) 1-9. doi:10.1103/PhysRevB.73.014104.

[15] S.P.S. Porto, J.F. Scott, Raman spectra of $\mathrm{CaWo}_{4}, \mathrm{SrWo}_{4}$, $\mathrm{CaMoo}_{4}$, and $\mathrm{SrMoo}_{4}$, Phys. Rev. 157 (1967) 716-719. doi:10.1103/PhysRev.157.716. 


\section{Figure captions}

Figure 1. Temperature dependence of heat capacity of $\mathrm{LaNb}_{0.9} \mathrm{Sb}_{0.1} \mathrm{O}_{4}, \mathrm{LaNb}_{0.8} \mathrm{Sb}_{0.2} \mathrm{O}_{4}$ and $\mathrm{LaNb}_{0.7} \mathrm{Sb}_{0.3} \mathrm{O}_{4}$ samples in low (a) and high (b) temperature ranges. $\mathrm{T}_{\mathrm{c}}(\mathrm{Sb} 10 \%)$ and $\mathrm{T}_{\mathrm{c}}$ ( $\mathrm{Sb} 20 \%$ ) are temperatures of the scheelite-fergusonite phase transition of $\mathrm{LaNb}_{0.9} \mathrm{Sb}_{0.1} \mathrm{O}_{4}, \mathrm{LaNb}_{0.8} \mathrm{Sb}_{0.2} \mathrm{O}_{4}$, respectively.

Figure 2. The heat capacity divided by temperature plotted as a function of $\mathrm{T}^{2}$. Solid lines correspond to the low temperature fitting by equation (1).

Figure 3. Debye temperature of $\mathrm{LaNb}_{1-\mathrm{x}} \mathrm{Sb}_{\mathrm{x}} \mathrm{O}_{4}(\mathrm{x}=0,0.1$ and 0.2$)$ and of $\mathrm{LaNb}_{1-\mathrm{y}} \mathrm{V}_{\mathrm{y}} \mathrm{O}_{4} \quad(\mathrm{y}=0,0.2$, 0.25) [11] plotted versus the scheelite - fergusonite transition temperatures.

Figure 4. The heat capacity vs. temperature for $\mathrm{LaNb}_{0.7} \mathrm{Sb}_{0.3} \mathrm{O}_{4}$. Points represent measured heat capacity, whereas the solid black curve is the fit to the measured data (Eq. (3)). Green (dashed) and red (dotted) lines correspond to the Debye and Einstein parts of the total heat capacity, respectively. 


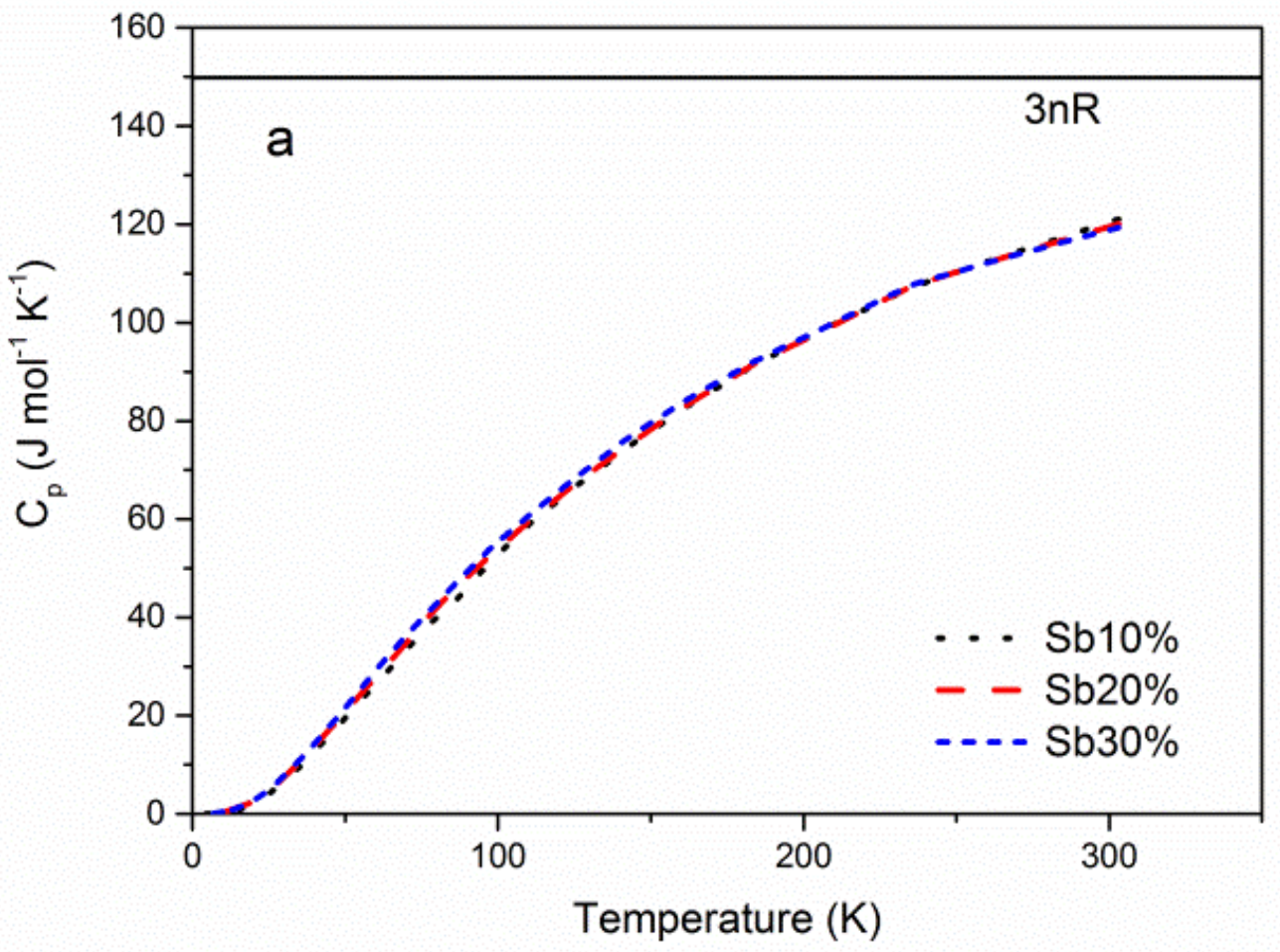




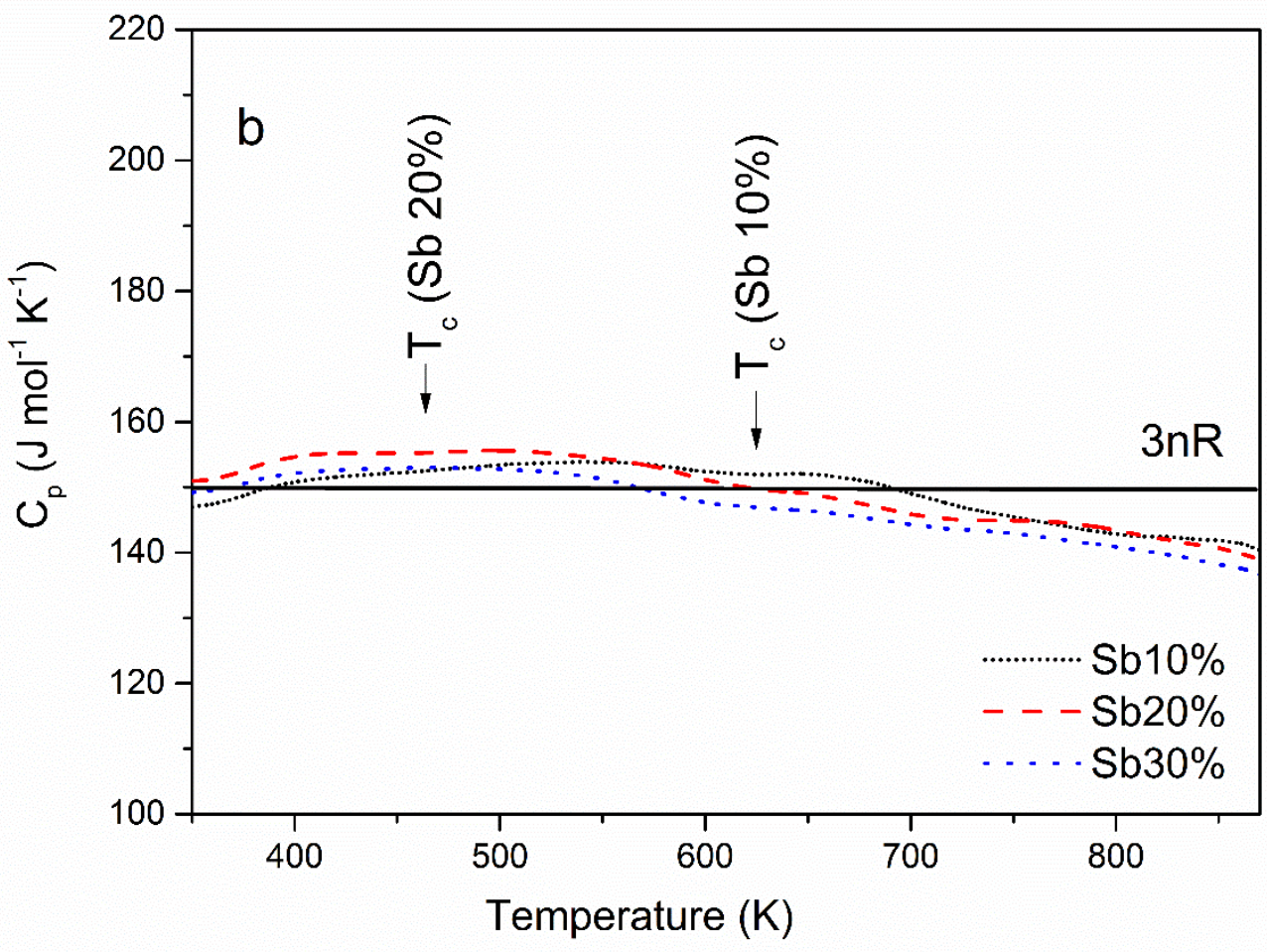




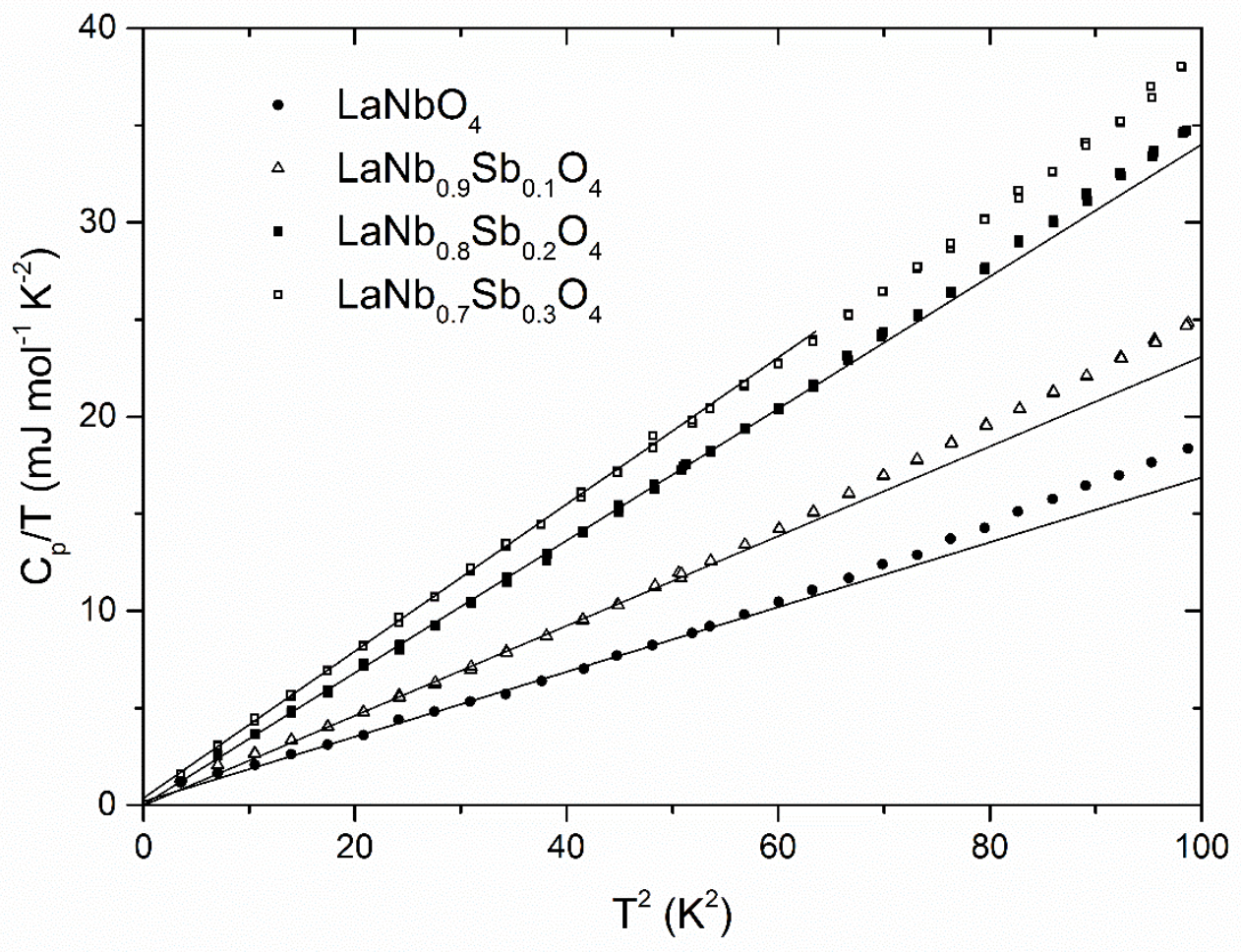




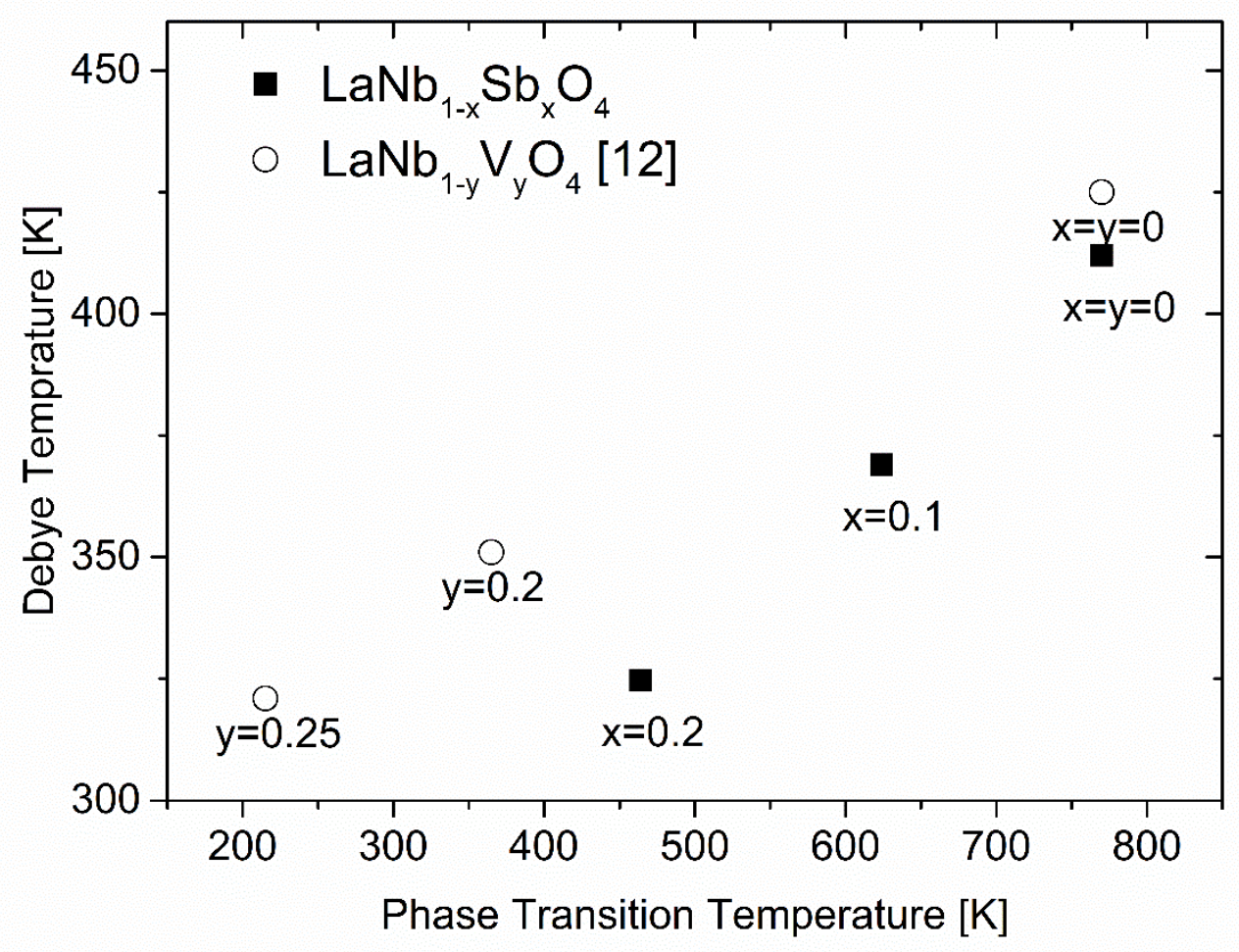




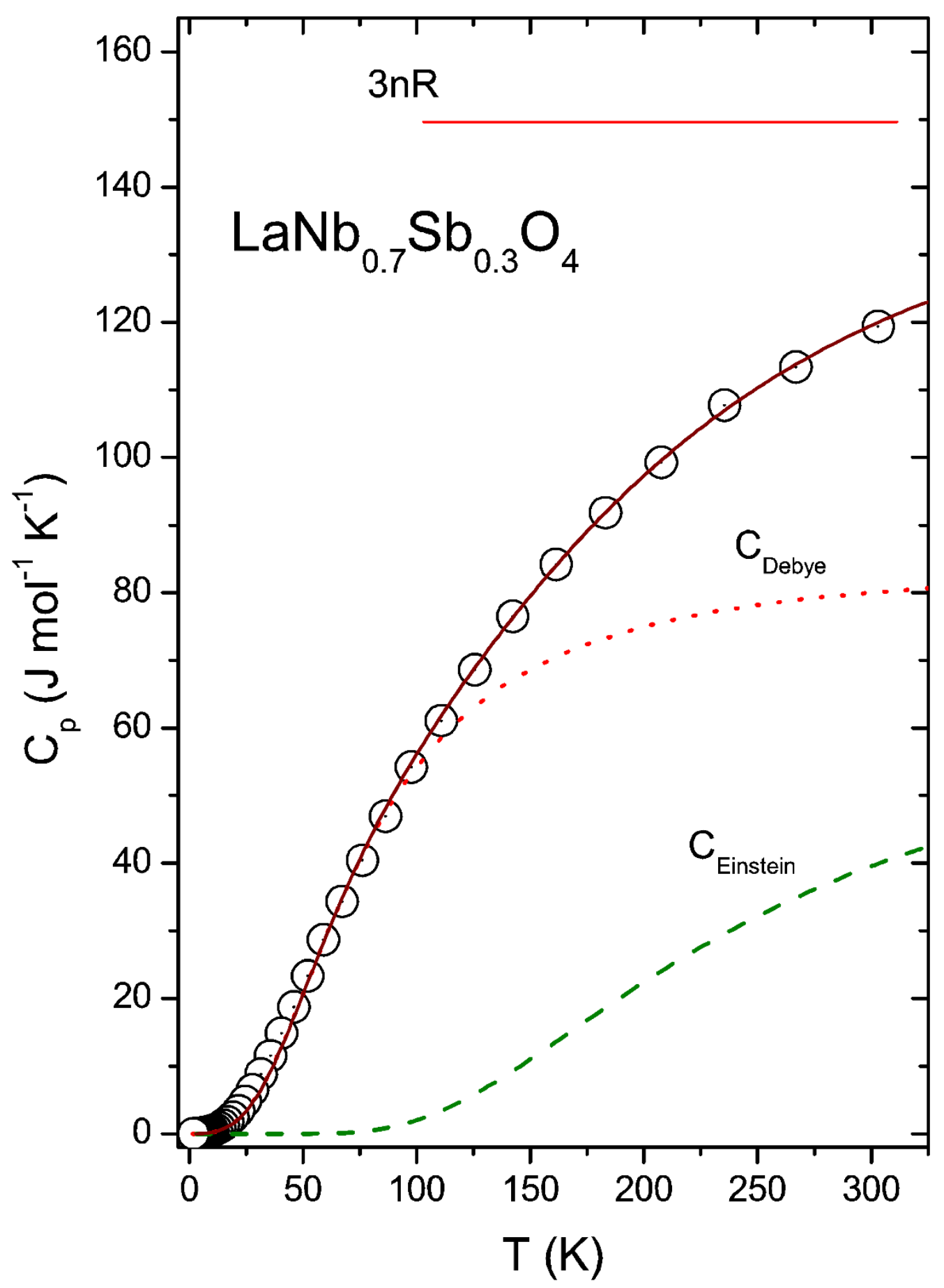




\section{TABLES}

Table 1. Debye (determined from fitting the data to equation (1) below $10 \mathrm{~K}$ ) and Einstein (from fitting the data to equation (3) below $300 \mathrm{~K}$ ) temperatures of antimony substituted lanthanum orthoniobates. The k parameter is the weight of the Debye term. For comparison also the Debye temperatures of vanadium substituted materials are given.

\begin{tabular}{ccccc}
\hline Composition & $\begin{array}{c}\text { Debye } \\
\text { temperature } \\
\theta_{\mathrm{D}}(\mathrm{K})\end{array}$ & $\begin{array}{c}\text { Einstein } \\
\text { temperature } \\
\theta_{\mathrm{E}}(\mathrm{K})\end{array}$ & $\mathrm{k}$ & Reference \\
\hline $\mathrm{LaNbO}_{4}$ & $412 \pm 2$ & $670 \pm 3$ & $0.49 \pm 0.01$ & \\
$\mathrm{LaNbO}_{4}$ & $425 \pm 2$ & - & & this work \\
$\mathrm{LaNb}_{0.9} \mathrm{Sb}_{0.1} \mathrm{O}_{4}$ & $369 \pm 1$ & $672 \pm 4$ & $0.48 \pm 0.02$ & {$[11]$} \\
$\mathrm{LaNb}_{0.8} \mathrm{Sb}_{0.2} \mathrm{O}_{4}$ & $325 \pm 2$ & $685 \pm 5$ & $0.48 \pm 0.01$ & this work \\
$\mathrm{LaNb}_{0.7} \mathrm{Sb}_{0.3} \mathrm{O}_{4}$ & $313 \pm 1$ & $700 \pm 6$ & $0.50 \pm 0.01$ & this work \\
$\mathrm{LaNb}_{0.8} \mathrm{~V}_{0.2} \mathrm{O}_{4}$ & $351 \pm 2$ & - & & this work \\
$\mathrm{LaNb}_{0.75} \mathrm{~V}_{0.25} \mathrm{O}_{4}$ & $321 \pm 1$ & - & & {$[11]$} \\
\hline
\end{tabular}

Table 2. Standard thermodynamic functions, heat capacity, heat content and standard entropy at given temperature, for antimony doped lanthanum orthoniobates from 2 to $300 \mathrm{~K}$.

\begin{tabular}{|c|c|c|c|c|c|c|c|c|c|}
\hline \multirow[b]{2}{*}{$\mathrm{T}$} & \multicolumn{3}{|c|}{$\mathrm{LaNb}_{0.9} \mathrm{Sb}_{0.1} \mathrm{O}_{4}$} & \multicolumn{3}{|c|}{$\mathrm{LaNb}_{0.8} \mathrm{Sb}_{0.2} \mathrm{O}_{4}$} & \multicolumn{3}{|c|}{$\mathrm{LaNb}_{0.7} \mathrm{Sb}_{0.3} \mathrm{O}_{4}$} \\
\hline & $C_{p, m}^{\circ}$ & $\Delta_{0}^{T} H_{m}^{\circ}$ & $\Delta_{0}^{T} S_{m}^{\circ}$ & $C_{p, m}^{\circ}$ & $\Delta_{0}^{T} H_{m}^{\circ}$ & $\Delta_{0}^{T} S_{m}^{\circ}$ & $C_{p, m}^{0}$ & $\Delta_{0}^{T} H_{m}^{\circ}$ & $\Delta_{0}^{T} S_{m}^{\circ}$ \\
\hline $\mathrm{K}$ & $\mathrm{J} / \mathrm{molK}$ & $\mathrm{kJ} / \mathrm{mol}$ & $\mathrm{J} / \mathrm{molK}$ & $\mathrm{J} / \mathrm{molK}$ & $\mathrm{kJ} / \mathrm{mol}$ & $\mathrm{J} / \mathrm{molK}$ & $\mathrm{J} / \mathrm{molK}$ & $\mathrm{kJ} / \mathrm{mol}$ & $\mathrm{J} / \mathrm{molK}$ \\
\hline 2 & 0.0030 & $3 \times 10^{-6}$ & 0.0021 & 0.0032 & $3 \times 10^{-6}$ & 0.0023 & 0.0038 & $3 \times 10^{-6}$ & 0.0025 \\
\hline 3 & 0.0074 & $8 \times 10^{-6}$ & 0.0041 & 0.0098 & $9.6 \times 10^{-5}$ & 0.0047 & 0.0116 & $1.1 \times 10^{-5}$ & 0.0054 \\
\hline 4 & 0.0152 & $2 \times 10^{-6}$ & 0.0072 & 0.0215 & $2.5 \times 10^{-5}$ & 0.0090 & 0.0258 & $3.0 \times 10^{-5}$ & 0.0106 \\
\hline 5 & 0.0286 & $4 \times 10^{-6}$ & 0.0120 & 0.0426 & $5.7 \times 10^{-5}$ & 0.0157 & 0.0487 & $6.7 \times 10^{-5}$ & 0.0187 \\
\hline 6 & 0.0494 & $8.0 \times 10^{-5}$ & 0.0190 & 0.0728 & $1 \times 10^{-4}$ & 0.0263 & 0.0839 & $1 \times 10^{-4}$ & 0.0305 \\
\hline 7 & 0.0805 & $1.4 \times 10^{-4}$ & 0.0288 & 0.1157 & $1 \times 10^{-4}$ & 0.0406 & 0.1313 & $1 \times 10^{-4}$ & 0.04688 \\
\hline 8 & 0.1220 & $2.4 \times 10^{-4}$ & 0.0422 & 0.1748 & $4 \times 10^{-4}$ & 0.0598 & 0.1935 & $4 \times 10^{-4}$ & 0.0683 \\
\hline 9 & 0.1793 & $4.0 \times 10^{-4}$ & 0.0598 & 0.2544 & $6 \times 10^{-4}$ & 0.0848 & 0.2779 & $6.4 \times 10^{-4}$ & 0.0959 \\
\hline 10 & 0.2517 & $6.1 \times 10^{-4}$ & 0.0823 & 0.3522 & $9 \times 10^{-4}$ & 0.1166 & 0.3870 & $9.7 \times 10^{-4}$ & 0.1307 \\
\hline 15 & 0.8954 & 0.0033 & 0.2898 & 1.1699 & 0.0044 & 0.3943 & 1.2413 & 0.0048 & 0.4285 \\
\hline 20 & 2.1747 & 0.0107 & 0.7074 & 2.6196 & 0.0137 & 0.9145 & 2.7685 & 0.0146 & 0.9808 \\
\hline 25 & 4.0894 & 0.0261 & 1.3871 & 4.7609 & 0.0318 & 1.7135 & 4.9666 & 0.0336 & 1.8217 \\
\hline 30 & 6.6280 & 0.0527 & 2.3492 & 7.4732 & 0.0623 & 2.8171 & 7.7708 & 0.0653 & 2.9667 \\
\hline 35 & 9.5462 & 0.0930 & 3.5856 & 10.4902 & 0.1070 & 4.1905 & 10.9132 & 0.1119 & 4.3972 \\
\hline 40 & 12.7459 & 0.1486 & 5.0667 & 13.8421 & 0.1677 & 5.8073 & 14.3576 & 0.1750 & 6.0763 \\
\hline 45 & 16.1262 & 0.2207 & 6.7619 & 17.3000 & 0.2456 & 7.6367 & 17.9497 & 0.2557 & 7.9739 \\
\hline 50 & 19.6018 & 0.3101 & 8.6399 & 20.8051 & 0.3408 & 9.6403 & 21.6258 & 0.3546 & 10.0544 \\
\hline 55 & 23.0589 & 0.4168 & 10.6710 & 24.3589 & 0.4537 & 11.7891 & 25.4133 & 0.4721 & 12.2912 \\
\hline 60 & 26.4649 & 0.5406 & 12.8240 & 27.9156 & 0.5844 & 14.0620 & 29.2297 & 0.6088 & 14.6677 \\
\hline
\end{tabular}




\begin{tabular}{|c|c|c|c|c|c|c|c|c|c|}
\hline 65 & 29.7695 & 0.6812 & 15.0727 & 31.3090 & & 16.4304 & 7893 & 7638 & \\
\hline 70 & 33.2960 & 0.8386 & 17.4043 & 34.8551 & 0.8977 & 18.8779 & 36.2586 & 0.9366 & 19.7061 \\
\hline 75 & 37.0006 & 1.0144 & 19.8278 & 38.5210 & 1.0812 & 21.4077 & 39.6593 & 1.1263 & 22.3236 \\
\hline 80 & 39.9954 & 1.2073 & 22.3165 & 41.9376 & 1.2825 & 24.0045 & 42.9219 & 1.3329 & 24.9883 \\
\hline 85 & 42.7770 & 1.4142 & 24.8247 & 45.2849 & 1.5005 & 26.6474 & 46.1447 & 1.5555 & 27.6871 \\
\hline 90 & 46.0585 & 1.6360 & 27.3589 & 48.2566 & 1.7346 & 29.3225 & 49.3134 & 1.7942 & 30.4147 \\
\hline 95 & 49.5255 & 1.8749 & 29.9420 & 51.1075 & 1.9830 & 32.0079 & 52.4636 & 2.0487 & 33.1654 \\
\hline 100 & 52.7955 & 2.1310 & 32.5684 & 53.9130 & 2.2456 & 34.7013 & 55.3835 & 2.3186 & 35.9338 \\
\hline 110 & 58.7978 & 2.6889 & 37.8818 & 59.4165 & 2.8123 & 40.0979 & 60.6488 & 2.8988 & 41.4594 \\
\hline 120 & 63.9130 & 3.3029 & 43.2205 & 64.5396 & 3.4322 & 45.4887 & 65.7396 & 3.5308 & 46.9554 \\
\hline 130 & 68.7875 & 3.9668 & 48.5322 & 69.4004 & 4.1025 & 50.8517 & 70.6504 & 4.2132 & 52.4149 \\
\hline 140 & 73.4610 & 4.6781 & 53.8010 & 73.9693 & 4.8194 & 56.1620 & 75.3511 & 4.9432 & 57.8227 \\
\hline 150 & 77.8624 & 5.4350 & 59.0216 & 78.2970 & 5.5810 & 61.4149 & 79.5519 & 5.7183 & 63.1687 \\
\hline 160 & 82.1782 & 6.2352 & 64.1845 & 82.5473 & 6.3852 & 66.6038 & 83.5961 & 5340 & 68.4320 \\
\hline 170 & 86.0857 & 7.0768 & 69.2855 & 86.3879 & 7.2302 & 71.7252 & 87.2079 & 7.3884 & 73.6103 \\
\hline 180 & 89.9231 & 7.9569 & 74.3147 & 90.1583 & 8.1129 & 76.7698 & 90.7455 & 8.2781 & 78.6951 \\
\hline 190 & 93.3052 & 8.8737 & 79.2710 & 93.4194 & 9.0316 & 81.7360 & 93.9302 & 9.2020 & 83.6897 \\
\hline 200 & 96.4859 & 9.8227 & 84.1378 & 96.4520 & 9.9809 & 86.6049 & 96.9566 & 10.1565 & 88.5847 \\
\hline 210 & 99.6220 & 10.8034 & 88.9221 & 99.5040 & 10.9607 & 91.3843 & 99.9870 & 11.1412 & 93.3885 \\
\hline 220 & 102.6171 & 11.8146 & 93.6256 & 102.6193 & 11.9713 & 96.0852 & 103.0305 & 12.1563 & 98.1101 \\
\hline 230 & 105.6122 & 12.8557 & 98.2532 & 105.7345 & 13.0130 & 100.7155 & 106.0739 & 13.2018 & 102.757 \\
\hline 240 & 108.1926 & 13.9258 & 102.8073 & 108.3120 & 14.0847 & 105.2761 & 108.5490 & 14.2764 & 107.3304 \\
\hline 250 & 110.2847 & 15.0182 & 107.2663 & 110.2510 & 15.1775 & 109.7370 & 110.3456 & 15.3709 & 111.7980 \\
\hline 260 & 112.3768 & 16.1315 & 111.6325 & 112.1900 & 16.2897 & 114.0989 & 112.1422 & 16.4833 & 116.1609 \\
\hline 270 & 114.4371 & 17.2657 & 115.9127 & 114.0894 & 17.4213 & 118.3691 & 113.8952 & 17.6137 & 120.4266 \\
\hline 273 & 115.0347 & 17.6099 & 117.1805 & 114.6330 & 17.7644 & 119.6328 & 114.3921 & 17.9561 & 121.6879 \\
\hline 280 & 116.4289 & 18.4200 & 120.1105 & 115.9015 & 18.5712 & 122.5510 & 115.5517 & 18.7609 & 124.5987 \\
\hline 290 & 118.4207 & 19.5942 & 124.2309 & 117.7137 & 19.7393 & 126.6498 & 117.2082 & 19.9247 & 128.6824 \\
\hline 298 & 120.0141 & 20.5480 & 127.475 & 119.1634 & 20.6870 & 129.8727 & 118.5334 & 20.8677 & 131.8899 \\
\hline 300 & 120.4125 & 20.7884 & 128.2791 & 119.5259 & 20.9255 & 130.6710 & 118.8647 & 21.1051 & 132.6839 \\
\hline
\end{tabular}

Table 3. Thermodynamic parameters of formation from oxides (f,ox) and elements (f) at $298 \mathrm{~K}$ for lanthanum orthoniobates.

\begin{tabular}{cccccc}
\hline Sample & $\begin{array}{c}\Delta \mathrm{H}_{\mathrm{f}, \mathrm{ox}} \mathrm{kJ} / \mathrm{mol} \\
{[7]}\end{array}$ & $\Delta \mathrm{G}_{\mathrm{f}, \mathrm{ox}}^{0} \mathrm{~kJ} / \mathrm{mol}$ & $\mathrm{S}^{0} \mathrm{~J} / \mathrm{molK}$ & $\Delta \mathrm{H}_{\mathrm{f}, \mathrm{kJ} / \mathrm{mol}}$ & $\Delta \mathrm{G}_{\mathrm{f}}^{0} \mathrm{~kJ} / \mathrm{mol}$ \\
& & & & & \\
\hline $\mathrm{LaNb}_{0.9} \mathrm{Sb}_{0.1} \mathrm{O}_{4}$ & $-132.85 \pm 1.53$ & $-131.34 \pm 2.40$ & $127.47 \pm 0.43$ & $-1706.90 \pm 2.53$ & $-1553.19 \pm 29.58$ \\
$\mathrm{LaNb}_{0.8} \mathrm{Sb}_{0.2} \mathrm{O}_{4}$ & $-132.01 \pm 1.53$ & $-131.20 \pm 2.40$ & $129.87 \pm 0.44$ & $-1707.75 \pm 2.54$ & $-1550.48 \pm 29.58$ \\
$\mathrm{LaNb}_{0.7} \mathrm{Sb}_{0.3} \mathrm{O}_{4}$ & $-126.41 \pm 1.54$ & $-126.21 \pm 2.40$ & $131.88 \pm 0.45$ & $-1713.34 \pm 2.54$ & $-1552.40 \pm 29.58$ \\
\hline
\end{tabular}

